antibodies in SPA and PA, to recommend systematically the eviction of etanercept in subjects with a moderate risk of developing anterior uveitis.

Disclosure of Interest: None declared

DOI: 10.1136/annrheumdis-2018-eular.3342

\section{SAT0283 $\quad$ SECUKINUMAB 150 MG PROVIDES SUSTAINED IMPROVEMENTS IN THE SIGNS AND SYMPTOMS OF ACTIVE ANKYLOSING SPONDYLITIS WITH HIGH RETENTION RATE: 4-YEAR RESULTS FROM THE PHASE III TRIAL, MEASURE 2}

H. Marzo-Ortega ${ }^{1}$, J. Sieper ${ }^{2}$, A. Kivitz ${ }^{3}$, R. Blanco ${ }^{4}$, M. Cohen ${ }^{5}$, E.M. Delicha ${ }^{6}$, S. Rohrer ${ }^{6}, \mathrm{H}$. Richards ${ }^{6}$ on behalf of MEASURE 2 Study Group. ${ }^{1} N I H R$ LMBRU, LTHT and LIRMM, UoL, Leeds, UK; ${ }^{2}$ University Clinic Benjamin Franklin, Berlin, Germany; ${ }^{3}$ Altoona Center for Clinical Research, Duncansville, USA $;{ }^{4}$ Hospital Universitario Marqués de Valdecilla, Santander, Spain; ${ }^{5}$ McGill University, Montreal, Canada; ${ }^{6}$ Novartis Pharma AG, Basel, Switzerland

Background: Secukinumab, a fully human monoclonal antibody that neutralises IL-17A, has shown significant and sustained improvement in the signs and symptoms of active ankylosing spondylitis (AS) through 3 years in the MEASURE 2 study (NCT01649375). ${ }^{1}$

Objectives: To report the longer-term (4 year) efficacy and safety of subcutaneous (s.c.) secukinumab $150 \mathrm{mg}$ in the MEASURE 2 study.

Methods: AS patients ( $p t s ; n=219$ ) were randomised to receive s.c. secukinumab $150 \mathrm{mg}, 75 \mathrm{mg}$ or placebo at baseline, Weeks (Wks) 1, 2 and 3 and every 4 weeks from Wk 4. At Wk 16, placebo-treated pts were re-randomised to receive secukinumab 150/75 mg. Efficacy results are reported for pts initially randomised to secukinumab $150 \mathrm{mg}$ and those who switched from placebo to secukinumab $150 \mathrm{mg}$ at Wk 16 . Safety analyses included all pts who received $\geq 1$ dose of secukinumab. Results are reported as observed.

Results: The retention rate from Wk 16 to 208 was 85\% (85/100) for secukinumab $150 \mathrm{mg}$. Sustained improvements were observed with secukinumab $150 \mathrm{mg}$ across all endpoints through 4 years (Table). These improvements were maintained regardless of prior exposure to anti-TNF therapy; greater responses were demonstrated in anti-TNF-naïve pts. Over the entire study period, the mean exposure $( \pm S D)$ to secukinumab was $1189.3 \pm 452.9$ days. Exposure-adjusted incidence rates (per 100 pt-years) with any secukinumab dose for selected adverse events were: serious infections/infestations (1.5), Candida infections (1.2), Crohn's disease (0.6), major adverse cardiovascular events $(0.6)$, uveitis $(0.6)$, and malignant/unspecified tumours (0.4).

Abstract SAT0283 - Table 1. Clinical improvements with secukinumab $150 \mathrm{mg}$ at Weeks 52 and 208

\begin{tabular}{lcccc}
\hline Variable & Week & \multicolumn{3}{c}{ Secukinumab 150 mg $^{\text {a }}$} \\
\cline { 3 - 5 } & & Total & $\begin{array}{c}\text { Anti-TNF- } \\
\text { naïve }\end{array}$ & $\begin{array}{c}\text { Anti-TNF- } \\
\text { IR }\end{array}$ \\
\hline ASAS20,\% responders (n) & 52 & $74.2(93)$ & $80.0(60)$ & $63.6(33)$ \\
& 208 & $73.3(86)$ & $74.6(59)$ & $70.4(27)$ \\
ASAS40,\% responders (n) & 52 & $57.0(93)$ & $63.3(60)$ & $45.5(33)$ \\
& 208 & $60.5(86)$ & $62.7(59)$ & $55.6(27)$ \\
BASDAI, mean change $\pm S D(n)$ & 52 & $-3.2 \pm 2.3$ & $-3.3 \pm 2.3(60)$ & $-3.0 \pm 2.1$ \\
& & $(93)$ & & $(33)$ \\
& 208 & $-3.2 \pm 2.3$ & $-3.5 \pm 2.4(59)$ & $-2.7 \pm 2.0$ \\
SF-36 PCS, mean change $\pm S D(n)$ & 52 & $7.6 \pm 7.7(94)$ & $8.0 \pm 7.5(61)$ & $6.9 \pm 8.1(33)$ \\
& 208 & $8.3 \pm 8.3(85)$ & $9.4 \pm 8.5(58)$ & $6.2 \pm 7.8(27)$ \\
ASAS partial remission,\% & 52 & $24.7(93)$ & $28.3(60)$ & $18.2(33)$ \\
responders (n) & 208 & $27.9(86)$ & $32.2(59)$ & $18.5(27)$ \\
\hline
\end{tabular}

ancludes placebo switchers. Data are reported as observed.

ASAS; Assessment in SpondyloArthritis International Society; BASDAI, Bath Ankylosing Spondylitis Disease Activity Index; IR, inadequate response; SD, standard deviation; SF-36 PCS, Short Form ${ }^{36}$ Health Survey Physical Component Summary; TNF, tumour necrosis factor

Conclusions: Secukinumab $150 \mathrm{mg}$ provided sustained improvement in the signs, symptoms and physical function in pts with AS through 4 years of treatment with $85 \%$ retention rate. The safety profile of secukinumab remained favourable and was consistent with previous reports. ${ }^{1-3}$

\section{REFERENCES:}

[1] Marzo-Ortega, et al. RMD Open 2017;3:e000592.

[2] Marzo-Ortega, et al. Ann Rheum Dis 2016;75:812-3.

[3] Baraliakos, et al. Clin Exp Rheumatol 2017.
Disclosure of Interest: H. Marzo-Ortega Grant/research support from: Janssen, Celgene, Speakers bureau: Janssen, Pfizer, AbbVie, Celgene, Novartis, UCB, J. Sieper Grant/research support from: AbbVie, Pfizer, Merck, Consultant for: for AbbVie, Pfizer, Merck, UCB, Novartis, Speakers bureau: AbbVie, Pfizer, Merck, UCB, A. Kivitz Grant/research support from: Altoona Centre for Clinical Research, Consultant for: Vertex, AbbVie, Amgen, Celgene, Horizon, Genetech, Janssen, Merck, Novartis, Pfizer, UCB, Genzyme, Sanofi, Regeneron, SUN Pharma Advanced Research, Boehringer Ingeleheim, R. Blanco Grant/research support from: Abbvie, MSD, Roche, Consultant for: AbbVie, Pfizer, Roche, Bristol-Myers, Janssen, Lilly, MSD, Speakers bureau: AbbVie, Pfizer, Roche, Bristol-Myers Janssen, Lilly, MSD, M. Cohen Consultant for: Abbvie, Amgen, BMS, Celgene, Janssen, Lilly, Merck, Novartis, Paladin, Pfizer, Roche, Sanofi, UCB, E. M. Delicha Employee of: Novartis, S. Rohrer Employee of: Novartis, H. Richards Employee of: Novartis

DOI: 10.1136/annrheumdis-2018-eular.3703

\section{SAT0284 AN ADD-ON TRAINING PROGRAM INVOLVING BREATHING EXERCISES, COLD EXPOSURE, AND MEDITATION ATTENUATES INFLAMMATION AND DISEASE ACTIVITY IN AXIAL SPONDYLOARTHRITIS}

G.A. Buijze ${ }^{1}$, H.M.Y. De Jong ${ }^{2}$, M. Kox ${ }^{3}$, D. van Schaardenburg ${ }^{2}$, R.M. van Vugt ${ }^{4}$, C. Popa ${ }^{5}$, P. Picckers ${ }^{3}$, D.L. Baeten ${ }^{2} .{ }^{1}$ Orthopaedic Surgery, ${ }^{2}$ Clinical immunology and rheumatology, Academic Medical Center, Amsterdam; ${ }^{3}$ Intensive Care Medicin, Radboud University Medical Centre, Nijmegen; ${ }^{4}$ Rheumatology, VU medical center, Amsterdam; ${ }^{5}$ Rheumatology, Sint Maartenskliniek, Nijmegen, Netherlands

Background: A training program involving breathing exercises, cold exposure, and meditation (further referred to as: 'add-on training program') was shown to exert immunomodulating properties in healthy individuals undergoing experimental endotoxemia.

Objectives: Assessment of safety and anti-inflammatory effects of the add-on training program in patients with axial spondyloarthritis $(\mathrm{axSpA})$.

Primary objectives: safety (24 weeks) and change in serum CRP levels (week 8 ) Secondary objectives: changes in erythrocyte sedimentation rate (ESR), serum calprotectin levels, disease activity as measured by the ASDAS-CRP and Bath Ankylosing Spondylitis Disease Activity Index (BASDAI), quality of life measures (SF-36, EQ-5D), and hospital anxiety and depression scale (HADS).

Methods: 24 patients with moderatly active axSpA (ASDAS >2.1 and $\mathrm{CRP}>5 \mathrm{mg} / \mathrm{L}$ ) were included in this trial. The intervention consisted of an 8 weeks add-on training program comprising three elements: breathing exercises (cyclic hyperventilation followed by breath retention), gradual cold exposure (immersions in ice cold water), and meditation (third eye meditation). An open-label randomised one-way crossover design was used to rule out regression to the mean by comparing an intervention group with a control group.

\section{CRP}

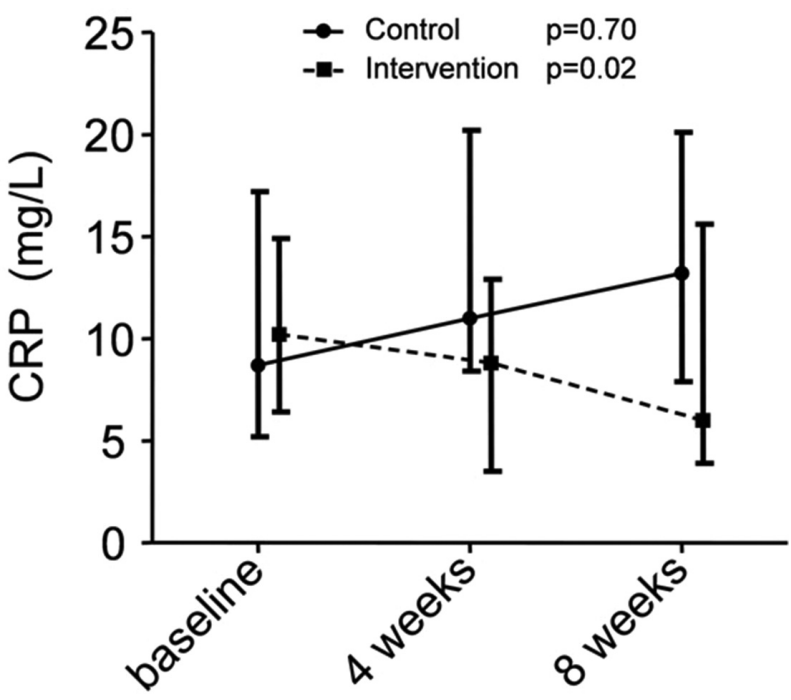

Results: There was no significant difference in adverse events between groups, with one serious adverse event (hypertensive crisis) occurring 8 weeks after end of the intervention and judged 'unrelated'. The study met its primary efficacy endpoint, with a significant decline in serum CRP at week 8 in the intervention group 